\title{
An Exploration of Interprofessional Education in Four Canadian Undergraduate Nursing Programs
}

\author{
Emily Donato \\ Laurentian University, edonato@laurentian.ca \\ Nancy Lightfoot \\ nlightfoot@laurentian.ca \\ Lorraine Carter \\ cartel1@mcmaster.ca \\ Leigh MacEwan Dr. \\ Laurentian University, Imacewan@laurentian.ca
}

Follow this and additional works at: https://qane-afi.casn.ca/journal

Part of the Nursing Commons

\section{Recommended Citation}

Donato, Emily; Lightfoot, Nancy; Carter, Lorraine; and MacEwan, Leigh Dr. (2020) "An Exploration of Interprofessional Education in Four Canadian Undergraduate Nursing Programs," Quality Advancement in Nursing Education - Avancées en formation infirmière: Vol. 6: Iss. 1, Article 5.

DOI: https://doi.org/10.17483/2368-6669.1201

This Article is brought to you for free and open access by Quality Advancement in Nursing Education - Avancées en formation infirmière. It has been accepted for inclusion in Quality Advancement in Nursing Education - Avancées en formation infirmière by an authorized editor of Quality Advancement in Nursing Education - Avancées en formation infirmière. 
An Exploration of Interprofessional Education in Four Canadian Undergraduate Nursing Programs

Cover Page Footnote

The research was funded by the Laurentian University Research Fund.

This article is available in Quality Advancement in Nursing Education - Avancées en formation infirmière: https://qaneafi.casn.ca/journal/vol6/iss $1 / 5$ 


\section{Introduction}

Interprofessional education (IPE) "occurs when two or more professions learn with, from and about each other to improve collaboration and the quality of care" (Centre for the Advancement of Interprofessional Education, 2002). IPE in health care emerged over 30 years ago at an international level and has become more prevalent in education, research, policy, and regulatory activities of health care professionals in the past decade (Reeves et al., 2012). The formal inclusion of IPE activities in undergraduate nursing programs in Canada occurred when the Canadian Association of Schools of Nursing (CASN, 2012) included IPE as part of the accreditation standards for nursing programs across Canada. As a result, nursing programs must demonstrate the integration of IPE throughout the undergraduate curriculum. Northern Ontario universities located in urban centres serve expansive geographic areas that include rural and, in some cases, remote communities. Although IPE may be occurring within these university settings, students from various professions may also have the opportunity to participate as interprofessional team members in rural and remote areas. The purpose of this research was to explore how four undergraduate university nursing programs in northern Ontario have integrated IPE into their curricula, including the opportunities and challenges of this work.

\section{Background}

Several themes were observed in the literature about the integration of IPE into undergraduate nursing curricula. The efficacy of the IPE intervention on student learning about other professions, teamwork, and collaborative care was examined. In other studies, IPE in classroom and clinical practice settings and IPE learning strategies were explored. The successes and challenges encountered integrating IPE curricula into programs were also frequent in the literature.

Much of the research focused on the efficacy of the IPE intervention. These included changes in how professions are viewed as team members, improvements in communication, learning how to work as part of a team, and the ability to provide collaborative care (Joyal et al., 2015; Nasir et al., 2017; Saylor et al., 2016).

The integration of IPE in clinical practice settings was also examined (Sick et al., 2014; Vanderzalm et al., 2013). Luebbers et al. (2017) found that a community-based interprofessional learning activity involving first-year medical and nursing students resulted in improved communication, collaboration, conflict management, team functioning, and a better understanding of how roles and teamwork improve the care being provided (Luebbers et al., 2017).

Some studies focused solely on classroom learning, while others focused on the inclusion of IPE in both classroom and practice settings. Balogun et al. (2015) conducted a cross-sectional study with 254 students from medicine, nursing, and an unidentified program who were involved in interactive case-based workshops. Overall results indicated improved knowledge and demonstration of interprofessional teamwork skills (Balogun et al., 2015). Ateah et al. (2011) found that students who had IPE experiences in classroom and clinical settings had significant improvements in their perceptions of other professionals as team members. There were very few articles about the integration of IPE throughout entire programs (Cahn, 2014; Ruiz et al., 2013).

Patient care simulation activities were often identified as valuable IPE learning strategies (Hudson et al., 2013). Saxell et al. (2009) used a cross-sectional study design to evaluate two simulation experiences involving medical, midwifery, and nursing students $(n=54, n=340)$. The 
study revealed an increase in both clinical and interprofessional knowledge. Student-led clinics are another strategy for IPE used in undergraduate nursing education (Ambrose et al., 2015; Sick et al., 2014).

Factors associated with the success of IPE integration include the following: administrative resource support, a dedicated coordinator role, the presence of faculty champions, and the cooperation of IPE facilitators in organizing and scheduling IPE activities (Cahn, 2014; Ruiz et al., 2013; Vanderzalm et al., 2013). Graybeal et al. (2010) explored what makes IPE programs successful and how institutions contribute to IPE success. Participants were administrators representing ten institutions of higher learning, including six from the United States and four from Canada. IPE success was dependent on the level of investment by administrators (mainly, the dean) and faculty (Graybeal et al., 2010).

The main challenges of IPE integration noted in the literature were the lack of faculty knowledge of IPE, a lack of IPE resources (human and space), the time-intensive nature of IPE activities, and difficulties with scheduling (Cahn, 2014; Ruiz et al., 2013; Vanderzalm et al., 2013). The need for funding was also cited as a challenge in successfully integrating IPE (Cahn, 2014; Graybeal et al., 2010).

IPE is evident in nursing curricula in a variety of ways as demonstrated by the literature. However, many of the cited studies were one-time interventions or involved voluntary extracurricular activities that did not include all the students in specified nursing programs (Ambrose et al., 2015; Ateah et al., 2011; Joyal et al., 2015; Nasir et al., 2017; Saylor et al., 2016). Despite the various barriers and challenges identified, no studies known to the author suggest that IPE should be excluded from health profession programs.

Recognizing the CASN requirement that IPE exist within undergraduate nursing programs, the following questions were explored in this study:

1. How are four northern Ontario undergraduate university nursing programs integrating IPE into their curricula?

2. What opportunities and challenges are experienced by northern Ontario undergraduate university nursing faculty and program administrators in integrating IPE into their curricula?

Normalization process theory (May et al., 2009) was selected as an appropriate framework for examining the integration of IPE into nursing curricula. A main premise of the theory is that to understand how a new practice is integrated, the actions of agents - those involved with the practice - must be assessed in relation to it. This thinking provides rationale for examining the ideas and actions experienced by those who deliver IPE within their respective nursing programs; that is, faculty members and directors. Within this study, the agents who contributed to the data sources included faculty members, directors, students, and others involved in IPE from within the larger context of the university. This theory will assist in framing the findings according to its main concepts and generative mechanisms.

\section{Methods}

\section{Methodology: Multiple Case Study}

Qualitative methodology was chosen to explore the research questions and enable detailed articulation of experiences related to IPE in undergraduate nursing programs. From among various 
qualitative options, multiple case study design was selected since it affords the researcher the opportunity to explore similarities and differences within and across cases (Baxter \& Jack, 2008; Yin, 2014). In this instance, the cases were undergraduate nursing programs in northern Ontario. An advantage of multiple case study design is that it allows the researcher to analyze various sources of data within and across settings, making the results more reliable (Baxter \& Jack, 2008). Multiple data-collection strategies, including interviews, focus groups, review of program documents and websites, and on-site program observations, were used to identify IPE-based content and delivery strategies in each undergraduate nursing program (Yin, 2014). The data collected provided information, ideas, and a variety of perspectives on what is occurring with IPE in the programs, including opportunities and challenges experienced, which is consistent with the main goal of case study research in obtaining the most accurate and complete information to answer the research questions (Stake, 2006).

\section{Data Collection}

The research took place at the locations of four undergraduate nursing programs in three northern Ontario universities in Sudbury, North Bay, and Thunder Bay, Ontario, from June 2016 to June 2017. In each instance, students apply to the university to be admitted to the nursing program. Undergraduate nursing programs to which students apply to a community college for admission and undergraduate university nursing programs of less than four years duration were excluded. Two of the nursing programs, while offered by the same institution, were different in language and structure. At this university, one program was offered in English and the other in French. The programs include different courses and sequencing of content, with overall programmatic goals of each of them leading to an undergraduate nursing degree.

A combined letter of invitation and consent form describing the study was sent as an email attachment to the administrative support staff at the involved school of nursing. This individual then forwarded the email to the program director and faculty members. The email script and letter were translated into French for the program offered in French.

The researcher's strategies of individual interviews, focus groups, institutional and program website reviews, document collection, and on-site program observations were guided by the first section of the "Interprofessional Education Assessment and Planning Instrument for Academic Institutions" (Association for Prevention Teaching and Research, 2009). This instrument was selected because it was developed to assist programs and institutions in the assessment of IPE within curriculum to plan future IPE goals (Greer \& Clay, 2010). Semistructured interview questions were created using the instrument domains as a guide. Each question included a section for the provision of relevant documentation. Additional questions addressing the second research question about the opportunities and challenges of integrating IPE within curriculum were also included. In total, 13 interview questions were used to guide the program director interviews and faculty focus groups. The questions were pilot-tested with a faculty member in another professional program before their use in the study.

Two to three days were spent at each institution for the interviewing, conducting focus groups, collecting program and course descriptions, reviewing the university's strategic plan, reviewing the program's website for evidence of IPE in program strategic planning, and documenting on-site observations. Program directors $(n=3)$ were interviewed in their offices for up to 1.5 hours per program (one director oversees two programs within the same institution). Faculty members $(n=10)$ participated in a focus group $(n=4)$ at each of their respective program 
sites for approximately 1.5 hours. Both full- and part-time faculty members who taught in different years of the program participated. One focus group member from each of three program sites was unable to participate in the focus group interview because of unforeseen circumstances. Because these individuals still wished to participate, they were given the opportunity to be interviewed after the focus group had occurred $(n=3)$. Although the request in the letter of invitation was that two faculty members per program year participate, faculty in the involved schools often teach in more than one year of the program. This circumstance resulted in focus group participant numbers being smaller than originally conceptualized.

Respondent validation occurred by returning verbatim transcripts of the interviews and focus group discussions to participants for review. Participants checked the accuracy of their data. Researcher bias from previous involvement in IPE activities was explored through reflective journaling during the data collection and analysis phases of the study (Creswell, 2013). These reflections were shared and discussed with the co-authors.

\section{Data Analysis}

Thematic analysis of data from interviews, focus groups, documents, websites, and on-site program observations was completed for each of the four programs (Braun \& Clarke, 2012). Coding was done manually and enabled the researcher to check for accuracy and practice validation. Directors and focus group participants were assigned numbers corresponding to the participant's program (e.g., D1, FG1M1). This strategy assisted in identification of quotations. Data from documents, websites, and on-site program observations were organized into a chart for each program, and each source was labelled for identification. These data sources were then analyzed and compared with the focus group and interview data.

Categorical aggregation was used to establish final themes for each program, which were then compiled in another chart with corresponding evidence from all data sources (Creswell, 2013). The codes and themes for each program were reviewed at different points in the analysis phase, as were the recordings, to ensure accurate representation of findings. Codes and themes were regularly discussed and reviewed with the co-authors. Finally, cross-case analysis was conducted. Codes and themes were compared, and five final themes were identified (Yin, 2014). Direct interpretation of single instances took place to ensure that unique IPE experiences within a case could be included in the findings (Creswell, 2013).

\section{Ethical Considerations}

Ethics review occurred at Laurentian University, Nipissing University, and Lakehead University. Research Ethics Boards from all institutions approved the study. The interviews and focus groups for the two Laurentian University undergraduate programs involved a bilingual facilitator obtained through a consulting company to prevent any perceived bias in the data collection process, ensure anonymity, and accommodate program language preferences. This process was important as the principal investigator is a member of this school of nursing.

\section{Findings}

The cross-case analysis described above resulted in five main themes: (1) varied understandings of IPE, (2) diverse IPE learning activities within curricula, (3) the requirement for support and resources for IPE and research, (4) student participation and leadership in IPE, and (5) limited IPE evaluation. Participants from one program identified a lack of accessibility to other 
health professionals as a resource issue for IPE. The five themes are described below with relevant supporting data.

\section{Varied Understandings of IPE}

Conceptually, IPE was understood in different ways which led to varied interpretations of its implementation. This theme emerged across all data sources and was prominent in the interviews with faculty members. One faculty member made this comment:

I don't know enough about IPE. I haven't myself had much exposure to it or practice with it or training or development in that, so it would be a real slow, hard learning thing I think, you know? For me it's like that lack of knowledge, you know that almost ignorance about what exactly it is and why it's important. (FG1M2)

Given little experience and understanding of IPE, implementation of IPE was difficult to embed and integrate within a program.

\section{Diverse IPE Learning Activities within Curricula}

IPE occurs in a variety of ways in the reviewed curricula. These ways include learning activities occurring in classrooms and clinical practice, as well as activities involving both formats. Simulation laboratory activities were reported as a popular means of IPE since case scenarios include students from different health professions working together. Such activities occur to varying degrees in all years of the programs. Similarly, integration of IPE learning objectives into courses has also occurred. In addition to mandatory learning activities, various voluntary IPE learning experiences in which not all students are involved or have the opportunity to participate were reported. In short, there is evidence of both IPE exposure and experience within the studied curricula; these words were used frequently by the participants during the interviews. The term exposure was used frequently when the participants described students working alongside other health professionals and in relation to guest speakers in the classroom setting. The term experience was used to describe IPE learning occurring mainly in simulation labs and clinical practice where students work collaboratively with other health professions students.

With respect to how IPE is threaded within curricula including the actual learning environment, a program director stated the following: "It's just threaded through our learning outcome that's really looking at relationships" (D1). A faculty member further indicated that "students are taught different cases by simulation, different clinical situations that may involve other health professionals" (FG3M4).

Both the mandatory and voluntary nature of IPE activities was described by participants. With respect to IPE occurring in laboratories, a faculty member commented on the mandatory nature of participation in IPE activities: "All students have to attend those labs ... those are mandatory" (FG1M3). By comparison, a director spoke about the voluntary nature of IPE simulation activities: "For the simulation, it is voluntary for the students so they can participate if they want" (D3, D4).

The idea of differentiation between IPE exposure and experience arose several times during the interviews. One faculty member reported:

I keep reading this IPE acronym and I keep thinking okay, so interprofessional education, but in my mind, I keep thinking interprofessional exposure. So, they are going to be 
exposed to these things but are they engaged in formal or organized education, learning with, from and about each other? (FG1M2)

\section{The Requirement for Support and Resources for IPE and Research}

Participants emphasized the importance of support and resources for successful IPE integration. Administrative support in recognizing IPE as integral to the education of health professionals was evident at the institutional level. Research support for IPE was also recognized as important in assisting faculty in understanding and incorporating IPE within curricula. Workload allocation for IPE was inconsistent, while space and scheduling challenges presented as resource issues. While some faculty provide IPE related activities, this work is on a voluntary basis or for a small credit allocation. Also, while positions dedicated to simulation have been created to lead IPE learning, such learning requires the use of a particular venue and often voluntary participation by students and faculty. In one case, a lack of access to other health professions was identified. This is a fundamental problem for IPE.

Administrative support by the institution beyond the program level was demonstrated through the presence of IPE language in strategic plans. IPE was often cited by administrators and was discussed frequently by program directors:

IPE has been identified by our institution and our program as required to be fully threaded and integrated ... Yeah, so they have strong IPE, you know, ideals ... every third word is about how interprofessional education is going to be integrated. (D2)

Although administrative support was identified in principle and on paper, various resources required for successful IPE integration were lacking. The participants emphasized that the lack of human resources available for IPE needs to be addressed. A leadership role focused on IPE integration within curricula was recommended as a means of organizing IPE opportunities and advocating for resources:

It would be really nice to, in the future, see workload allocation... or whoever is on that committee having a .5 sort of like from an advocacy perspective for how we can get IPE organized better, having ... say a .5 for being the IPE lead and then having a stand-in item on the agenda, the faculty meetings, whatever for an update on IPE stuff. (FG1M1)

A faculty member felt that such a role could also provide support for IPE teaching and research:

I just think if they set up or even hired someone that has some experience in IPE to come to faculty council and say ... "we'd like to help to work with you guys on how you can bring this together for teaching and for research." (FG1M2)

The scheduling of IPE learning activities and the need for spaces for these activities were commonly cited as issues by faculty members involved in IPE learning activities. A faculty member from one program emphasized the following: "The schedule logistics, funding, location ... I would say that place is really important, funding, human support" (FG3M1).

On-site observations of programs further revealed a lack of adequate learning spaces required to house IPE activities, although for some programs, new IPE learning spaces were being planned. 
As noted earlier, the challenge of access to other health professionals was experienced by one program. These other professions were regarded to be necessary resources for IPE integration into the curriculum by the participants. During one of the focus groups, this idea was further discussed by two faculty members:

It does not occur in each of the four years as much as it should, and as much as some people think it does (FG2M1).

I think there are two reasons that it happens. One is that we don't really have access to all the people that you would normally-like, if we were a larger institution, there would be different professions accessible to us. (FG2M2)

The above circumstance relates to the unique geographic characteristics of Northern Ontario and impacts access to a variety of health professions students to facilitate IPE. At the same time, the participant representing the program did indicate that it has partnered successfully with other available health care program students to implement IPE within the curriculum.

\section{Student Participation and Leadership in IPE}

Nursing students were reported to be involved in IPE learning activities on a voluntary basis. Such activities were substantiated by documents and websites and included simulation and student-led activities such as clinics. Participation in voluntary simulation experiences demonstrated an interest by some students in learning with, from, and about the other health professionals accessible to them. With respect to IPE in simulation, one faculty member shared that it "is very attractive to the student population, they really like the hands on, they like to learn. For those, I see a lot of them, before participating" (FG3M1).

The student-led clinics happen at different points in the programs and, according to one faculty member, are evolving:

The students come together and they take the lead on making that happen. So, it's something that our program is invited to be involved in, but it's definitely not something that we can take any credit for. I think the student-led clinic, the principle looks like a nice opportunity. I don't know what's going on with it but if they can find a way to get it off the ground. (FG1M2)

\section{Limited IPE Evaluation}

Some evaluation of IPE learning has occurred in the programs in a variety of ways. Most of these evaluations were student evaluations that were part of course evaluations; some were related to the clinical practice setting. One faculty member described a student assignment: "It's a scholarly paper ... they have to look up the topic, they have to talk about the experience of being in the IPE experience, and then they have to reflect on it" (FG2M2).

Simulation laboratory IPE initiatives have also had some preliminary evaluation. A program director shared the following: "We are evaluating what we have done. These are pilot projects; we're exploring to see if there are things we could do differently" (D3, D4).

Documents such as accreditation reports and program assessments for IPE provided evidence of evaluation of the programs and progress with IPE integration. Despite limited evaluation work, activities to improve IPE learning within programs were reported. 


\section{Discussion}

The findings of this study provide insight into how four undergraduate nursing programs in northern Ontario have integrated IPE into their curricula. Importantly, these findings are grounded in the perspectives of faculty members and program directors. Review of websites and documents and observations of program settings add to this picture of what has been occurring across the programs. The opportunities and challenges experienced by faculty and program directors in integrating IPE within their curricula are made apparent by application of the generative mechanisms of normalization process theory.

May et al. (2009) proposed that practices become embedded as the result of individual and collective action, such as the participants' varied understandings of IPE. Cognitive participation and collective action by agents occurred despite the variations in coherence or understanding of IPE. As agents, the faculty and directors in this study provided evidence of working and partnering with students and other health professionals to embed and implement IPE learning activities into various formats and to diverse skill levels.

In accordance with normalization process theory, levels of IPE implementation were occurring in the programs, despite the varied understandings of IPE. Since generative mechanisms are not linear but interrelated, it is not unusual that IPE was occurring within the curricula despite variations in coherence. The types of IPE learning activities were likely influenced by these interpretations of IPE.

The varied understandings of IPE suggest a need for faculty development regarding IPE. In the literature, lack of faculty knowledge regarding IPE is identified as a barrier to successful IPE integration (Cahn, 2014; Graybeal et al., 2010; Ruiz et al., 2013; Vanderzalm et al., 2013). In their work, Lawlis et al. (2014) found that faculty development programs are instrumental to facilitating IPE. In this study and others found in the literature, faculty indicated their need for a better understanding of IPE through faculty development and support for IPE research. In summary, the varied understandings of IPE have likely contributed to the ways IPE was being implemented and evaluated in the four programs under study. IPE evaluation across programs is also an area that requires development. This work could involve exploration of evaluation strategies within the IPE literature and selection of an evaluation strategy when planning IPE curricula (Coffey \& Anyinam, 2015). There are several frameworks and strategies for the integration and evaluation of IPE in the literature that provide methods to assess, plan, implement, and evaluate IPE curricula (Cranford \& Bates, 2015; Pardue, 2015; Sterrett et al., 2015).

IPE through simulation and student-led initiatives is happening within the programs. Simulation is the strategy that faculty discussed most frequently. The prevalence of IPE through simulation as a learning strategy has been noted in a systematic review of IPE in nursing by Rutherford-Hemming and Lioce (2018). Student-led clinics were also identified at various stages of development across the four nursing programs. $\mathrm{Ng}$ and $\mathrm{Hu}$ (2017) emphasized the role of student-run clinics as an emerging trend for IPE in Canada.

The voluntary nature of IPE activities, including simulation laboratories and student-led initiatives, was discussed by the study participants at some length. Although attempts are being made to integrate IPE within curricula, voluntary activities including regular occurrences and pilot projects are the primary instances of IPE. At the same time, some mandatory IPE initiatives are integrated into courses through course objectives. All of this is in line with a review of IPE 
education in Canada, which found that many of the IPE activities reflected in the literature were voluntary and occurred principally in clinical practice settings (Grant et al., 2016).

The idea of IPE exposure was prominent in the comments of the participants, with some mention of immersion in an IPE clinical experience. In many instances, participants indicated that the IPE learning activity was more of an exposure and not a full experience. The University of Toronto's Framework for the Development of Interprofessional Education Values and Core Competencies outlines the movement from IPE exposure (introduction), to immersion (development), to competence (entry to practice) (Nelson et al., 2014). Use of this IPE framework ensures that the three core competencies of values and ethics, communication, and collaboration are achieved along a continuum. Using this framework as a reference point, most of the IPE activities discussed in the findings of this study fall within the exposure phase.

The space, time/scheduling, and human resources required for IPE were emphasized as main challenges to its integration. Where such supports and resources were present, the participants commented on how successful the integration of IPE learning activities was. These findings are consistent with those of Reeves et al. (2012) and those from a literature review exploring barriers and enablers of sustaining IPE (Lawlis et al., 2014). Dedicated spaces for IP enhance cohesion and the collaborative experience as a whole (Brewer et al., 2017). The need for funding of IPE-related positions to lead and organize IPE activities within the curriculum was mentioned by participants. Rutherford-Hemming and Lioce (2018) have identified lack of funding for resources as a barrier to IPE.

The challenge of accessing students in other health professions programs for one particular program pertains to resources. In this case, the northern context and geographic location influenced the availability of specific types of health professions that could be learning with, from, and about each other. In one study, students from several other professions were brought to northern Ontario from another Ontario university to participate in IPE learning with students from other unspecified universities on placement at three sites in northwestern Ontario (Salvatori et al., 2007). The idea of accessing rural and remote areas as part of the experience of IPE integration is not new. Deutschlander et al. (2013) found that IPE education in rural or underserved areas may influence recruitment of health professionals to these areas postgraduation. The practice of bringing other health professions students into a specific geographic area might enhance IPE learning for nursing students within the program.

A possible limitation to this research pertains to the transferability of results because of the varied contexts of each program. Some of the findings are specific to Northern Ontario and each program's institutional context. Dependability of the results may have been affected by the review of large amounts of data and interpretation of findings, even though attempts were made by the researcher to decrease potential bias. At the same time, the triangulation of data sources from the four separate programs contributes to the credibility of the findings. Finally, the faculty who consented to be involved in the focus groups or who agreed to be interviewed may have had an interest in IPE and/or have had IPE workload allocation, thus presenting a selection bias.

\section{Conclusions}

The state of IPE in northern Ontario as described has implications for educators, administrators, and institutions in this part of Ontario and possibly across Canada. Faculty development must occur to meet the needs of those enacting the integration of IPE. Such faculty development includes a review of IPE competencies, IPE research, and the many frameworks that 
now exist for nursing programs in relation to the planning, implementation, and evaluation of IPE within curricula. The Centre for the Advancement of Interprofessional Education recently developed Interprofessional Education Guidelines for pre-licensure health professions and continuing professional education. These guidelines can assist with the development and assessment of IPE processes (Barr et al., 2017). Student involvement needs to be encouraged and supported by faculty and administration in the development of student-led initiatives in IPE learning through the provision of resources (e.g., providing adequate learning spaces; reducing scheduling conflicts) and by ensuring students receive some credit or clinical practice hours toward their course work. Additionally, administrators need to support faculty and ensure that resources are in place for IPE, including research (Wilhelmsson et al., 2009). Finally, innovative IPE learning approaches and research involving technology are required to engage students from other health professions in rural and northern contexts to help broaden the scope of their learning. Additionally, partnerships with other educational institutions and practice settings can be initiated and established within these geographic areas to facilitate IPE opportunities. This way, students across a variety of professional programs beyond the geographic boundaries of the northern context can learn from and with each other. 


\section{References}

Ambrose, E., Baker, D., Mahal, I., MicFlikier, A., \& Holmqvist, M. (2015). Interprofessional experiences at a student-run clinic: Who participates and what do they learn? Journal of Research in Interprofessional Practice and Education, 5(2), 1-16. https://doi.org/10.22230/jripe.2015v5n2a197

Association for Prevention Teaching and Research. (2009). Interprofessional education assessment and planning instrument for academic institutions. http://www.aptrweb.org/?page=ipe_assessment

Ateah, C. A., Snow, W., Wener, P., MacDonald, L., Metge, C., Davis, P., Fricke, M., Ludwig, S., \& Anderson, J. (2011). Stereotyping as a barrier to collaboration: Does interprofessional education make a difference? Nurse Education Today, 31(2), 208-213. https://doi.org/10.1016/j.nedt.2010.06.004

Balogun, S. A., Rose, K., Thomas, S., Owen, J., \& Brashers, V. (2015). Innovative interprofessional geriatric education for medical and nursing students: Focus on transitions in care. Quarterly Journal of Medicine, 108, 465-471. https://doi.org/10.1093/qjmed/hcu226

Barr, H., Ford, J., Gray, R., Helme, M., Hutchings, M., Low, H., Machin, A., \& Reeves, S. (2017). CAIPE [2017] Interprofessional education guidelines. https://www.caipe.org/resources/publications/caipe-publications/caipe-2017interprofessional-education-guidelines-barr-h-ford-j-gray-r-helme-m-hutchings-m-low-h$\underline{\text { machin-reeves-s }}$

Baxter, P., \& Jack, S. (2008). Qualitative case study methodology: Study design and implementation for novice researchers. The Qualitative Report, 13(4), 544-559. http://www.nova.edu/ssss/QR/QR13-4/baxter.pdf

Braun, V., \& Clarke, V. (2012). Thematic Analysis. In H. Cooper (Ed.), APA handbook of research methods in psychology, Vol. 2. Research designs: Quantitative, qualitative, neuropsychological, and biological (pp. 57-71). American Psychological Association. https://doi.org/10.1037/13620-004

Brewer, M. L., Flavell, H. L., \& Jordon, J. (2017). Interprofessional team-based placements: The importance of space, place and facilitation. Journal of Interprofessional Care, 31(4), 429-437. https://doi.org/10.1080/13561820.2017.1308318

Cahn, P. S. (2014). In and out of the curriculum: An historical case study in implementing interprofessional education. Journal of Interprofessional Care, 28(2), 128-133. https://doi.org/10.3109/13561820.2013.872607

Canadian Association of Schools of Nursing. (2012). CASN Accreditation program: Updates to key elements and interpretations. Unpublished addendum to CASN Accreditation Standards.

Centre for the Advancement of Interprofessional Education. (2002). Definition of interprofessional education. http://www.caipe.org.uk/about-us/defining-ipe/

Coffey, S., \& Anyinam, C. (2015). Interprofessional health care practice. Pearson Canada. 
Cranford, J. S., \& Bates, T. (2015). Infusing interprofessional education into the nursing curriculum. Nurse Educator, 40(1), 16-20. https://doi.org/10.1097/NNE.0000000000000077

Creswell, J. W. (2013). Qualitative inquiry and research design. Choosing among five approaches (3rd ed.). Sage Publications.

Deutschlander, S., Suter, E., \& Grymonpre, R. (2013). Interprofessional practice education: Is the "interprofessional' component relevant to recruiting new graduates to underserved areas? Rural and Remote Health, 13, 2489. http://www.rrh.org.au/publishedarticles/article_print_2489.pdf

Grant, R. E., Goldman, J., LeGrow, K., MacMillan, K. M., van Soeren, M., \& Kitto, S. (2016). A scoping review of interprofessional education within Canadian nursing literature. Journal of Interprofessional Care, 30(5), 620-626. https://doi.org/10.1080/13561820.2016.1192589

Graybeal, C., Long, R., Scalise-Smith, D., \& Zeibig, E. (2010). The art and science of interprofessional education. Journal of Allied Health, 39(Suppl. 1), 232-237. https://www.ncbi.nlm.nih.gov/pubmed/21174045

Greer, A. G., \& Clay, M. C. (2010). Interprofessional education assessment and planning instrument for academic institutions. Journal of Allied Health, 39(Suppl. 1), 224-231. https://www.ncbi.nlm.nih.gov/pubmed/21174044

Hudson, C. E., Sanders, K., \& Pepper, C. (2013). Interprofessional education and prelicensure baccalaureate nursing students: An integrative review. Nurse Educator, 38(2), 76-80. https://doi.org/10.1097/NNE.0bO13e318282996d

Joyal, K. M., Katz, C., Harder, N., \& Dean, H. (2015). Interprofessional education using simulation of an overnight inpatient ward shift. Journal of Interprofessional Care, 29(3), 268-270. https://doi.org/10.3109/13561820.2014.944259

Lawlis, T. R., Anson, J., \& Greenfield, D. (2014). Barriers and enablers that influence sustainable interprofessional education: A literature review. Journal of Interprofessional Care, 28(4), 305-310. https://doi.org/10.3109/13561820.2014.895977

Luebbers, E. L., Dolansky, M. A., Vehovec, A., \& Petty, G. (2017). Implementation and evaluation of a community-based interprofessional learning activity. Journal of Interprofessional Care, 31(1), 91-97. https://doi.org/10.1080/13561820.2016.1237936

May, C. R., Mair, F., Finch, F., MacFarlane, A., Dowrick, C., Treweek, S., Rapley, T., Ballini, L., Ong, B. N., Rogers, A., Murray, E., Elwyn, G., Légaré, F., Gunn, J., \& Montori, V. M. (2009). Development of a theory of implementation and integration: Normalization process theory. Implementation Science, 4, Article 29. https://doi.org/10.1186/1748-5908$\underline{4-29}$

Nasir, J., Goldie, J., Little, A., Banerjee, D., \& Reeves, S. (2017). Case-based interprofessional learning for undergraduate healthcare professionals in the clinical setting. Journal of Interprofessional Care, 31(1), 125-128. https://doi.org/10.1080/13561820.2016.1233395

Nelson, S., Tassone, M., \& Hodges, B. (2014). Creating the health care team of the future: the Toronto model for interprofessional education and practice. Cornell University Press. 
$\mathrm{Ng}, \mathrm{E} .$, \& Hu, T. (2017). A survey of Canadian interprofessional student-run free clinics. Journal of Interprofessional Care, 31(6), 781-784.

https://doi.org/10.1080/13561820.2017.1346590

Pardue, K. (2015). A framework for the design, implementation, and evaluation of interprofessional education. Nurse Educator, 40(1), 10-15. https://doi.org/10.1097/NNE.0000000000000093

Reeves, S., Tassone, M., Parker, K., Wagner, S. J., \& Simmons, B. (2012). Interprofessional education: An overview of key developments in the past three decades. Work, 41, 233245. https://doi.org/10.3233/WOR-2012-1298

Ruiz, M. G., Ezer, H., \& Purden, M. (2013). Exploring the nature of facilitating interprofessional learning: Findings from an exploratory study. Journal of Interprofessional Care, 27(6), 489-495. https://doi.org/10.3109/13561820.2013.811640

Rutherford-Hemming, T., \& Lioce, L. (2018). State of interprofessional education in nursing: A systematic review. Nurse Educator, 43(1), 9-13. https://doi.org/10.1097/NNE.0000000000000405

Salvatori, P. S., Berry, S. C., \& Eva, K. W. (2007). Implementation and evaluation of an interprofessional education initiative for students in the health professions. Learning in Health and Social Care, 6(2), 72-82. https://doi.org/10.1111/j.1473-6861.2007.00152.x

Saxell, L., Harris, S., \& and Elarar, L. (2009). The collaboration for maternal and newborn Health: Interprofessional maternity care education for medical, midwifery and nursing students. Journal of Midwifery and Women's Health, 54(4), 314-320. https://doi.org/10.1016/j.jmwh.2009.03.017

Saylor, J., Vernoony, S., Selekman, J., \& Cowperthwait, A. (2016). Interprofessional education using a palliative care simulation. Nurse Educator, 41(3), 125-129. https://doi.org/10.1097/NNE.0000000000000228

Sick, B., Sheldon, L., Ajer, K., Wang, Q., \& Zhang, L. (2014). The student-run free clinic: An ideal site to teach interprofessional education? Journal of Interprofessional Care, 28(5), 413-418. https://doi.org/10.3109/13561820.2014.907779

Stake, R. E. (2006). Multiple case study analysis. Guilford Press.

Sterrett, S. E., Hawkins, S. R., Hertweck, M. L., \& Schreiber, J. (2015). Developing communities of interprofessional practice: Using a communities of practice framework for interprofessional education. Nurse Educator, 40(1), E1-E4. https://doi.org/10.1097/NNE.0000000000000109

Vanderzalm, J., Hall, M. D., McFarlane, L., Rutherford, L., \& Patterson, S.K. (2013). Fostering interprofessional learning in a rehabilitation setting: Development of an interprofessional clinical learning unit. Rehabilitation Nursing, 38(4), 178-185. https://doi.org/10.1002/rnj.78

Wilhelmsson, M., Pelling, S., Ludvigsson, J., Hammar, M., Dahlgren, L., \& Faresjo, T. (2009) Twenty years experiences of interprofessional education in Linköping - Ground-breaking and sustainable. Journal of Interprofessional Care, 23(2), 121-133. https://doi.org/10.1080/13561820902728984 
Quality Advancement in Nursing Education - Avancées en formation infirmière, Vol. 6, Iss. 1 [2020], Art. 5

Yin, R. K. (2014). Case study research: Design and methods (5th ed.). Sage Publications. 